\title{
ISO 31000:2009 Enterprise and Supply Chain Risk Management: A Longitudinal Study
}

\section{Sime Curkovic, Thomas Scannell, Bret Wagner}

Management Department, Center for Integrated Supply Management, Haworth College of Business, Western Michigan University, Kalamazoo, USA.

Email: sime.curkovic@wmich.edu, thomas.scannell@wmich.edu,bret.wagner@wmich.edu

Received September $10^{\text {th }}, 2013$; revised October $10^{\text {th }}$, 2013; accepted October $15^{\text {th }}, 2013$

Copyright (c) 2013 Sime Curkovic et al. This is an open access article distributed under the Creative Commons Attribution License, which permits unrestricted use, distribution, and reproduction in any medium, provided the original work is properly cited.

\begin{abstract}
This research attempts to fill two recently identified gaps in Supply Chain Risk Management (SCRM) research, specifically the lack of a common framework and limited empirical research. This research first attempts to determine if ISO 31000:2009 provides a foundation to advance SCRM research by standardizing the SCRM research framework, terms, and risk treatment categories. Secondly, it attempts to determine if ISO 31000:2009 is a useful framework for managers to link SCRM to enterprise risk management (ERM) when executing SCRM. Currently, there is no research that explicitly links SCRM to the ISO 31000:2009 ERM standard. In this study, longitudinal survey data were analyzed, and follow-up discussions with managers were used to achieve the research purpose. It was determined that current SCRM research frameworks have similarities with each other, but they also diverge to some extent. The ISO 31000:2009 framework encompasses existing SCRM frameworks, but it is more exhaustive than that, which includes the need for developing a strategic context for risk management and for ongoing performance monitoring. It is suggested that ISO 31000:2009 provides a foundation for extending and advancing future SCRM research. It was also found that firms increasingly recognize the importance of systematic SCRM, but SCRM integration and skills are lacking. Topics for future research are proposed, including for example using ISO 31000:2009 as a research foundation, potential outsourcing of SCRM, appropriate organizational structure for SCRM, deployment of IT, and SCRM return on investment.
\end{abstract}

Keywords: Supply Chain Risk Management (SCRM); Enterprise Risk Management (ERM); IS0 31000:2009; Empirical; Longitudinal

\section{Introduction}

This Enterprise risk management (ERM) has been identified as a key strategic issue for business [1]. ERM presents a systematic approach toward managing corporate risks and it is a driver of company success [2,3]. However, adoption of ERM is not widespread [4]. ISO 31000:2009 is intended to support firms in their development and implementation of ERM strategy, structure, and process. Supply chain risk management (SCRM) has also taken on increased importance for firms, particularly as global sourcing has increased, companies have "leaned out" their supply chains, and product cycle times have become shorter. ERM is supported by SCRM by positively impacting customer satisfaction, costs, delivery and quality performance [5-8].

It has been suggested that despite an increasing litera- ture focused on ERM, the broad topic of ERM research is under-developed [1]. It has also been suggested that despite more research into SCRM, there are gaps in SCRM research as well [9]. This research is motivated by the idea that SCRM research will advance more effecttively if there is a consensus on what constitutes SCRM and the assessment that there is a lack of empirical SCRM research [7]. Two primary research questions are explored: 1) How do the current SCRM frameworks proposed by researchers map to the ISO 31000:2009 ERM standard? and, 2) What are the past, current, and future risks and risk management strategies reported by firms, and how do they map to ISO 31000:2009? Longitudinal data are analyzed to address the questions. Managerial implications and future research suggestions are developed based on the responses. 
The findings indicate that despite firms that are reporting an increased recognition of SCRM importance, SCRM approaches tend to be ad-hoc rather than integrated. It was also found that actual SCRM practices and proposed SCRM frameworks all map well to ISO 31000. Thus, for practitioners, ISO 31000 provides a foundation for linking SCRM to ERM, and for developing SCRM strategy and processes. For researchers, ISO 31000 provides a reasonable framework that could accelerate the understanding of SCRM.

In the next section, the literature review discusses gaps in SCRM research, explores the ISO 31000 ERM standard, compares existing SCRM frameworks with ISO 31000, then briefly identifies supply risks and SCRM practices. The methodology is then presented and the survey data results are then summarized. Finally, the results are interpreted and discussed, using qualitative feedback from practitioners to support the discussion.

\section{Literature Review}

\subsection{CRM Research Gaps}

The advancement of any field or strategic initiative (e.g., Total Quality Management, Mass Customization, Just-InTime Manufacturing, Supply Chain Risk Management) requires empirically based research whose thrust is the development and validation of frameworks, concepts and measurement instruments. For example, the TQM discipline required that an operational definition and standardized framework be developed and validated in order for theory building to advance (see for example [10-15]). By doing so, the TQM discipline moved from the important contributions of anecdotes and case studies (the current state of SCRM research) to testable models and specific research hypotheses, linking the theoretical concept of TQM to empirical indicants. Operational definitions and standardized frameworks have contributed to TQM theory-building by identifying the constructs associated with TQM, developing scales for measuring these constructs, and empirically validating the scales. The SCRM research is in its infancy stages and requires the same type of research.

Global competitive landscapes and increasingly complex supply chain processes and partnerships, coupled with increased requirements to comply with regulations, laws and industry guidelines has heightened awareness that firms may benefit from a systematic approach to risk management. SCRM has garnered significant academic, consultant, and practitioner interest over the last decade as a way to not only mitigate risk, but to take advantage of risk opportunities [2,16]. SCRM is a process for identifying, analyzing and proactively planning responses to a portfolio of risks $[17,18]$.

Though effective SCRM can provide significant bene- fits for a firm [2,3], a relatively small percentage of firms have a detailed understanding of this integrated process, and adoption of SCRM is rather limited [18]. Ad hoc approaches to risk management by various "silos" in an organization leads to duplication of resources, uncoordinated planning, and less efficient and effective risk management processes [2]. Varying frameworks have been proposed to support and standardize implementation of systematic SCRM. Sample frameworks include the Joint Australia/New Zealand AS/NZ 4360-2004, the Turnbull Guidance, and the ISO 31000 standards for risk management.

SCRM and related frameworks are not without detractors. There is a lack of empirical research into the effectiveness of SCRM in general [2] and the specific frameworks in particular. Other detractors note that implementing SCRM requires a substantial commitment of resources (time, personnel, money) that aren't likely to be available during lean times, and a cultural shift of the entire organization [19] without an appropriate return on such efforts [20]. However, with appropriate planning and execution, SCRM frameworks may be implemented by any organization, from large to small firms [18,19]. Other SCRM frameworks have also been proposed [8, 21-23]. There are many similarities in these frameworks, though there is no consensus on the scope of SCRM [7]. In some cases, the concepts are the same, but the terms used are slightly different (e.g., risk assessment versus risk evaluation) and some frameworks do not explicitly identify key processes (e.g., monitoring and review).

Sodhi, Son and Tang [7] identified multiple SCRM research gaps and recommended ways to close the gaps. One gap they identified is a lack of consensus regarding the definition and scope of SCRM. They suggested that there is a great need to reach a consensus on such issues in order to better communicate with company executives and practitioners, and to more quickly advance SCRM research. They also suggest that SCRM is a subset or extension of ERM [7]. Given their suggestions, the ISO 31000 ERM framework, developed by and for practitioners, was identified as a potential consensus framework for SCRM that could fill the research gap. Another gap they identified was a lack of empirical SCRM research, particularly in regard to understanding current practice. This empirical research focuses on current practice and is one important first step toward filling the empirical research gap.

\subsection{ERM, ISO 31000:2009 and SCRM Frameworks}

Enterprise risk management (ERM) is a holistic approach to identify and manage corporate-wide risks to achieve long-term success [3]. Though ERM is an increasingly important topic for practitioners and researchers [2], it is not widely adopted [24]. ISO 31000 Risk Management 
Principles, released by the International Organization for Standardization (ISO), presents a set of principles, framework and processes for achieving ERM [25]. Given the clout and impact of prior ISO standards, ISO 31000 will likely become a globally adopted format for ERM [26]. ISO 31000 was built upon the foundation established by the AS/NZS 4360 process [27], which has been used and tested over time. ISO 31000 intends to support risk management across all functions of an organization, including supply, finance, and operations for example. ISO Guide 73:2009 [28], provides definitions to support understanding and implementation of ISO 31000.

ISO 31000 identifies eleven principles for effective ERM: create value; be an integral part of all processes; be integrated with decision making; explicitly examine uncertainty; be systematic, structured and timely; rely on best available information; be tailored to specific needs; account for human and cultural factors; be transparent and inclusive; be responsive to change; and facilitate continual improvement [25]. The ISO 31000 framework emphasizes integration of risk management practices throughout the value chain to support corporate decisionmaking [25].

ISO 39000:2009 Clause 5, Risk Management Process, is the focus of this research. The process consists of five integrated segments (Figure 1). There is a high level of integration and iteration within the risk management processes [29]. Clause 5.2, Communication and Consultation, calls for continuous risk information collection and dissemination by involving all stakeholders. Clause 5.3, Establishing the Context, develops objectives and sets the foundation (e.g., culture, organization, resources, responsibilities, etc.) for achieving those objectives.

Clause 5.4, Risk Assessment, presents three interdependent activities: identifying risks, analyzing risks, and evaluating risks. Risk identification (5.4.2) is a systematic process to understand and categorize risk, and to identify risk drivers. Risk analysis (5.4.3) involves evaluation of risk impacts and the likelihood of occurrence. Risk evaluation (5.4.4) prioritizes risks, and identifies which risks may require treatment. Some risks may be acceptable while others are not. An "acceptable risk" is one for which the perceived benefits outweigh the costs of a possible treatment.

Risk treatment (5.5) selects the appropriate options for treating or modifying risks. Such options include: acceptance of risk to realize competitive advantages; avoidance of risk by not engaging in the activity; reduction or removal of the impact or probability of the risk; or distribution of risk by sharing or transferring the risk. Monitoring and review (5.6) involves ongoing analysis of the risks encountered, and assessment of risk treatment effectiveness.

SCRM frameworks have also been proposed [8,21-23]. There are many similarities in these frameworks, though

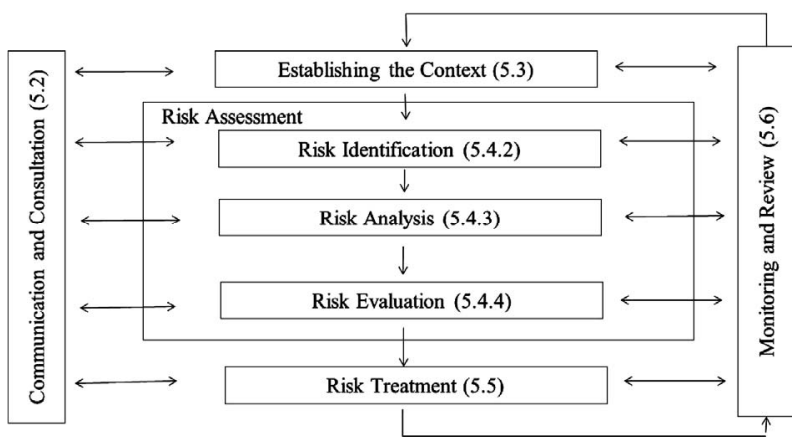

Figure 1. ISO 31000:2009 Clause 5 process for managing risk.

there is no consensus on the scope of SCRM [7]. In some cases, the concepts are the same, but the terms used are slightly different (e.g., risk assessment versus risk evaluation) and some frameworks do not explicitly identify key processes (e.g., monitoring and review). Table 1 compares four SCRM frameworks with the ISO 31000:2009 standard.

Though SCRM frameworks and ISO 31000 share overlapping concepts, the ISO 31000 standard provides a more comprehensive framework. It requires "establishment of the context," a critical step for holistic risk management and for linking SCRM with ERM. ISO 31000 also emphasizes "monitoring and review" to create a closed-loop process. ISO 31000 was used in this research to explore SCRM rather than any of the proposed SCRM frameworks, because it is more comprehensive and is expected to become an internationally adopted approach to risk management [26]. Further, Sodhi, Son, and Tang [7] suggest that SCRM is an integral component of ERM, and that there is a need to reach consensus regarding the scope of SCRM in order to advance research in this field. ISO 31000 provides the framework for integrating SCRM and ERM, and for driving consensus on the scope of SCRM.

\subsection{Supply Chain Risks and Practices}

Firms face multiple supply risks, whether in combination or isolation, such as supplier reliability/failure, currency exchange, commodity cost volatility, banking and government regulations, bankruptcy, material shortages, logistics failures, demand change, diminishing capacities, return policy, port security, legal liabilities, insurance coverage, tax issues, natural disasters, intellectual property, skilled labor, language, strikes, property laws, infrastructure, contract failure, contamination, fraud, information, theft, etc. [8,30-33]. Each risk might require a specific SCRM technique [34].

There are a variety of definitions for SCRM. In general, SCRM may be defined as managing supply risks through collaboration or coordination with supply partners to achieve sustainable profitability and continuity 
Table 1. Comparison of proposed SCRM frameworks to ISO 31000:2009.

\begin{tabular}{|c|c|c|c|c|}
\hline ISO 31000:2009 & $\begin{array}{l}\text { Hallikasa et al., } \\
2004\end{array}$ & $\begin{array}{l}\text { Kleindorfer \& Saad, } \\
2005\end{array}$ & $\begin{array}{c}\text { Manuj \& Mentzer, } \\
2008\end{array}$ & $\begin{array}{l}\text { Tummala \& Schoenherr, } \\
2011\end{array}$ \\
\hline \multicolumn{5}{|c|}{ 5.2 Communication and Consultation } \\
\hline \multicolumn{5}{|l|}{ 5.3 Establishing the context } \\
\hline \multirow[t]{2}{*}{ 5.4.2 Risk identification } & Risk identification & $\begin{array}{l}\text { Specifying sources of risks } \\
\text { and vulnerabilities }\end{array}$ & Risk identification & Risk Identification \\
\hline & & & & Risk measurement $^{*}$ \\
\hline 5.4.3 Risk analysis & \multirow{2}{*}{ Risk assessment } & \multirow[t]{2}{*}{ Assessment } & \multirow{2}{*}{$\begin{array}{l}\text { Risk assessment and } \\
\text { evaluation }\end{array}$} & Risk assessment \\
\hline 5.4.4 Risk evaluation & & & & Risk evaluation \\
\hline \multirow{3}{*}{ 5.5 Risk treatment } & & Mitigation & $\begin{array}{l}\text { Selection of appropriate risk } \\
\text { management strategies }\end{array}$ & \multirow{3}{*}{$\begin{array}{l}\text { Risk mitigation \& } \\
\text { contingency plans }\end{array}$} \\
\hline & $\begin{array}{c}\text { Decision and } \\
\text { implementation of risk } \\
\text { management actions }\end{array}$ & & $\begin{array}{l}\text { Implementation of supply } \\
\text { chain risk management } \\
\text { strategies }\end{array}$ & \\
\hline & & & $\begin{array}{l}\text { Mitigation of supply } \\
\text { chain risks }\end{array}$ & \\
\hline 5.6 Monitoring and review & Risk monitoring & & & Risk control \& monitoring \\
\hline
\end{tabular}

* Covered in ISO 31000:2009 in Section 5.3.5 Risk criteria.

[35]. SCRM treatment options include evaluation and trust building [36], use of dual sources [37], environmental scanning [38], combined capacity reservation contracts and spot markets [39], supply chain modeling and information systems integration [40], qualification and use of capable suppliers 23], supplier quality management initiatives [41], buffer inventory [35], contingency plans [22], credit analysis [42], strategic sourcing and flexibility [43], forward buying or hedging [33] and supplier development [44]. Despite the plethora of risks and risk management approaches, few firms have a structured SCRM approach [45].

\section{Methods}

The focus of this research is exploratory in nature (rather than confirmatory). Field-based data and survey collection methods were used to ensure that the important variables were identified. It also helped us develop an understanding of why these variables might be important $[46,47]$. This research examined how current SCRM research frameworks and actual business practices align with the ERM standard ISO 31000:2009, and identified past, current and future SCRM experiences of firms. A purposeful sample was used in this exploratory research $[46,48]$. Key criterion included that the company would agree to identify an informed respondent, reply in a timely manner to a scaled and open ended survey, and be willing to participate in follow-up questions as needed. All targeted respondents support supply chain management higher education, and are involved with professsional supply associations such as the Institute of Supply
Management, Association of Operations Management, and Council of Supply Chain Management Professionals. The method followed was similar to the grounded theory development methodology suggested by Glasser and Strauss [49]. In instances where a well-developed set of theories regarding a particular branch of knowledge does not exist, Eisenhardt [46] and McCutcheon and Meredith [50] suggest that theory building can best be done through limited sample sizes.

Several industries were chosen for this study to achieve some level of generalizability. The first survey was sent to 67 contacts in 2009, yielding 46 responses (68\% response rate). The second survey was distributed two years later in 2011 to 58 contacts, yielding 38 usable responses (66\% response rate). Both surveys were nearly identical with regard to format, and all items discussed in this paper are identical in terms of content. For each survey, the non-respondents suggested that they either: 1) didn't have time to fill out the survey within the window of time provided; or 2) company policy prevented them from fully participating. Early to late respondent survey comparisons were made to analyze potential non-response bias [51]. The mean values for seven randomly selected questions were compared between the first $25 \%$ of responses and the last $25 \%$ of responses. No statisticcally significant differences were found between responses. The majority of non-respondents indicated that either company policy prevented them from participation in this particular survey or that resources were constrained when the survey was distributed.

Similar to much of the research in operations strategy, a single industry ideally would have been chosen. Fo- 
cusing on a single industry controls for variance due to industry specific conditions. Industries may also differ in the consensus understanding of the meaning of terms. Controlling for industry effects can compensate for variability between industries, in terms of work force management, general market conditions, degree of unionizetion, etc. Controlling for these industry-specific differences through the focus on one industry also means that firm-specific variance is highlighted in subsequent analyses. Restricting the sample permits the control of several variables that often differ between industries, including the scope and complexity of risk management concerns. At the same time, one would have to identify a specific industry where the types of SCRM issues and range of programs used offer sufficient variability for study. This variability within that sample would then provide a basis for external generalizability. However, no single industry was selected because there has not been one that has been a leader in implementing progressive SCRM strategies. Furthermore, no single industry has already been the focus of many empirical studies that address SCRM. Given these circumstances and the infancy stages of this topic area, aggregation of survey results among widely varying industries was justified and the route taken.

\section{Data Analysis}

Four profile characteristics of respondents to each survey were compared using t-tests assuming unequal variances (Tables 2 through 5). There were no statistically signifycant differences in any of the characteristics, suggesting that comparison of other survey data was valid. Table 6 lists respondent job titles for each survey.

Table 2. Industry profile.

\begin{tabular}{ccc}
\hline Industry & Survey $\mathbf{1}$ 2009 & Survey 2 2011 \\
\hline Aerospace/Defense & 2 & 4 \\
Agriculture & 1 & 1 \\
Automotive & 14 & 10 \\
Chemicals & 0 & 3 \\
Consumer Products & 2 & 1 \\
Electronics & 1 & 1 \\
Food & 1 & 1 \\
Fuel, Utilities and Power & 0 & 2 \\
Health Care & 1 & 2 \\
House Building and Construction & 0 & 11 \\
Manufacturing & 16 & 0 \\
Transportation & 1 & 1 \\
Other & 7 & 38 \\
Total & 46 & \\
\hline
\end{tabular}

t-test $(\mathrm{p}=0.13)$.

Table 3. Sales profile.

\begin{tabular}{|c|c|c|}
\hline Annual Sales & Survey 12009 & Survey 22011 \\
\hline$\$ 10 M-S 49 M$ & 3 & 1 \\
\hline$\$ 50 \mathrm{M}-\$ 99 \mathrm{M}$ & 2 & 3 \\
\hline$\$ 100 M-\$ 499 M$ & 6 & 2 \\
\hline$\$ 500 \mathrm{M}-\$ 999 \mathrm{M}$ & 3 & 4 \\
\hline$\$ 1 B-\$ 9 B$ & 15 & 7 \\
\hline$\$ 10 \mathrm{~B}-\$ 49 \mathrm{~B}$ & 12 & 15 \\
\hline$\$ 50 \mathrm{~B}-\$ 99 \mathrm{~B}$ & 3 & 3 \\
\hline Over \$100B & 2 & 3 \\
\hline Total & 46 & 38 \\
\hline
\end{tabular}

t-test $(\mathrm{p}=0.25)$. 
Table 4. Employment profile.

\begin{tabular}{ccc}
\hline Employees & Survey $\mathbf{1}$ 2009 & Survey 2 2011 \\
\hline Under 50 & 1 & 0 \\
$50-99$ & 1 & 1 \\
$100-499$ & 4 & 3 \\
$500-999$ & 2 & 2 \\
$1000-4999$ & 10 & 3 \\
$5000-9999$ & 4 & 23 \\
Over 10,000 & 24 & 38 \\
\hline
\end{tabular}

t-test $(\mathrm{p}=0.48)$.

Table 5. Ownership.

\begin{tabular}{ccc}
\hline Ownership & Survey $\mathbf{1 2 0 0 9}$ & Survey 2 2011 \\
\hline Privately Owned & 13 & 11 \\
Publicly Owned & 30 & 25 \\
Public/Privately Owned & 3 & 2 \\
Total & 46 & 38 \\
\hline
\end{tabular}

t-test $(\mathrm{p}=0.87)$.

Table 6. Respondent titles.

\begin{tabular}{ccc}
\hline Title & Survey 1 2009 & Survey 2 2011 \\
\hline Supply Chain Leader/Manager/Coordinator/Buyer & $66 \%$ & $54 \%$ \\
Production/Operations/Materials Manager & $22 \%$ & $29 \%$ \\
Analyst & $6 \%$ & $17 \%$ \\
Account/Sales Director & $6 \%$ & 0 \\
\hline
\end{tabular}

\section{SCRM Process}

Survey data were grouped according to ISO 31000 Clause 5 process segments. The data tables are sorted by the highest mean score or the highest ranking based on survey two data. "Agree/disagree" questions were scaled from "1 = strongly disagree" to "7 = strongly agree". "Extent of use" questions were scaled from "1 = not used" to "7 = extensively used."

Communication and Consultation Clause 5.2: There were no statistically significant differences in the communication and consultation practices (Table 7). Information gathering and establishing communications with suppliers remain paramount approaches. However, concerns exist whether supply risk information is accurate and readily available. There may be a somewhat increased use of data warehousing and demand signal repositories, though neither change was statistically sig- nificant.

Establishing the Context Clause 5.3: Contextual factors were grouped according to need, approach, budget, and organization (Table 8), consistent with general guidelines proposed by ISO 31000. There was a statistically significant increase in the recognition that much can go wrong in a supply chain without systematic risk analysis. SCRM is recognized as a strategic issue, but the lack of a single set of tools or technologies makes implementation a challenge. The supply chain organization seems to lack key risk management skills and has a limited understanding of corporate risk management strategy.

SCRM budgets are shown in Table 9 . The response rate was not $100 \%$ for this question due to competitive concerns. There was no significant difference in spending plans between the two data sets. Table 10 indicates that 
Table 7. SCRM and Clause 5.2 communication and consultation.

\begin{tabular}{|c|c|c|c|c|c|}
\hline \multirow[b]{2}{*}{ Item } & \multicolumn{2}{|c|}{ Survey 12009} & \multicolumn{2}{|c|}{ Survey 22011} & \multirow{2}{*}{ t-test } \\
\hline & Mean & SD & Mean & SD & \\
\hline Information gathering & 5.67 & 1.21 & 5.51 & 1.54 & 0.61 \\
\hline Forecasting techniques (e.g., to pre-build \& carry additional inventory of critical items) & 4.61 & 1.57 & 4.79 & 1.56 & 0.60 \\
\hline Our company uses real-time inventory information and analytics in managing the supply chain. & 4.76 & 1.52 & 4.61 & 1.66 & 0.68 \\
\hline Data warehousing & 4.09 & 1.76 & 4.59 & 1.54 & 0.16 \\
\hline $\begin{array}{l}\text { Visibility (detailed knowledge of what goes on in other parts of the supply } \\
\text { chain - e.g., finished goods inventory, material inventory, WIP, pipeline inventory, actual } \\
\text { demands and forecasts, production plans, capacity, yields, and order status) }\end{array}$ & 4.26 & 1.29 & 4.24 & 1.46 & 0.95 \\
\hline Supply chain risk information is accurate and readily available to key decision makers. & 3.87 & 1.57 & 3.81 & 1.68 & 0.87 \\
\hline Network design analysis programs & 3.25 & 1.94 & 3.41 & 1.40 & 0.68 \\
\hline
\end{tabular}

Table 8. SCRM and Clause 5.3 establishing the context.

\begin{tabular}{|c|c|c|c|c|c|}
\hline \multirow{2}{*}{$\begin{array}{c}\text { Item } \\
\text { NEED }\end{array}$} & \multicolumn{2}{|c|}{ Survey 12009} & \multicolumn{2}{|c|}{ Survey 22011} & \multirow{2}{*}{$\frac{\text { t-test }}{\mathrm{p}}$} \\
\hline & Mean & SD & Mean & SD & \\
\hline Without a systematic analysis technique to assess risk, much can go wrong in a supply chain. & 5.54 & 1.03 & 6.19 & 0.97 & $0.00^{*}$ \\
\hline Managing supply chain risk is an increasingly important initiative for our operations. & 5.65 & 1.30 & 5.92 & 1.19 & 0.33 \\
\hline My workplace plans on evaluating or implementing supply chain risk tools and technologies. & 4.98 & 1.58 & 5.08 & 1.91 & 0.79 \\
\hline We are very concerned about our supply chain resiliency, and the failure implications. & 4.78 & 1.59 & 4.81 & 1.65 & 0.94 \\
\hline \multicolumn{6}{|l|}{ APPROACH } \\
\hline There is no single set of tools or technologies on the market for managing supply chain risks. & 5.24 & 1.49 & 5.50 & 1.34 & 0.41 \\
\hline We are currently using some form of supply chain risk management tools and services. & 4.46 & 1.93 & 5.03 & 1.83 & 0.17 \\
\hline Managing supply chain risks is driven by reactions to failures rather being proactively driven. & 4.39 & 1.36 & 4.19 & 1.67 & 0.57 \\
\hline Proactive risk mitigation efforts applied to the supply chain is common practice for us. & 4.33 & 1.49 & 4.19 & 1.76 & 0.71 \\
\hline Supply chain risk initiatives are driven from the bottom up rather than top down. & 3.67 & 1.56 & 3.70 & 1.75 & 0.94 \\
\hline \multicolumn{6}{|l|}{ BUDGET } \\
\hline We do plan on investing nontrivial amounts in managing supply chain risks. & 4.30 & 1.86 & 4.17 & 1.46 & 0.71 \\
\hline We have a dedicated budget for activities associated with managing supply chain risks. & 3.65 & 1.96 & 3.89 & 2.27 & 0.61 \\
\hline Funding for managing supply chain risks will come from a general operations budget. & 3.91 & 1.94 & 3.81 & 2.03 & 0.81 \\
\hline Our spending intentions for managing supply chain risks are very high. & 3.37 & 1.58 & 3.08 & 1.54 & 0.41 \\
\hline Supply chain employees understand government legislation \& geopolitical issues. & 3.70 & 1.26 & 3.73 & 1.61 & 0.92 \\
\hline I fully understand the activities being performed by our risk management group. & 4.00 & 1.86 & 3.70 & 1.54 & 0.43 \\
\hline My workplace uses supply chain risk managers who work closely with corporate risk mgmt. & 2.53 & 1.74 & 2.64 & 1.81 & 0.79 \\
\hline We are planning to outsource all or some of our risk management functions. & 2.25 & 1.28 & 2.14 & 1.22 & 0.69 \\
\hline
\end{tabular}


Table 9. SCRM budget.

\begin{tabular}{ccc}
\hline Spend & Survey 1 2009 Survey 2 2011 \\
\hline Less than $\$ 500,000$ & 21 & 16 \\
$\$ 1,000,000-\$ 5,000,000$ & 3 & 3 \\
$\$ 500,000-\$ 1,000,000$ & 1 & 1 \\
More than $\$ 5,000,000$ & 3 & 4 \\
Total & 28 & 24 \\
t-test $(\mathrm{p}=0.50)$ & & \\
\hline
\end{tabular}

Table 10. Projected change in SCRM budget.

\begin{tabular}{ccc}
\hline Change & Survey $\mathbf{1 2 0 0 9}$ & Survey 2 2011 \\
\hline Increase & 20 & 14 \\
Decrease & 6 & 3 \\
No change & 17 & 21 \\
Total & 43 & 38 \\
t-test $(\mathrm{p}=0.23)$ & & \\
\hline
\end{tabular}

Table 11. Ownership of SCRM investments.

\begin{tabular}{ccc}
\hline Department & Survey 1 2009 & Survey 2 2011 \\
\hline Risk Management & 0 & 1 \\
Supply Chain/Purchasing & 40 & 33 \\
Legal & 0 & 0 \\
Logistics & 1 & 0 \\
Manufacturing/Operations & 2 & 1 \\
IT & 0 & 1 \\
Accounting/Finance & 1 & 1 \\
Quality & 0 & 0 \\
Other & 0 & 0 \\
Total & 44 & 37 \\
t-test (p = 0.99) & & \\
\hline
\end{tabular}

most firms will keep SCRM spending at current levels or increase spending in the future. Table 11 suggests that purchasing/supply generally takes ownership of SCRM investments, though Table 12 suggests the SCRM budget generally does not come from a specific SCRM budget.

Risk Assessment Clause 5.4: There were no statisticcally significant differences in the risk assessment practices (Table 13). Specific risk factors such as supplier reliability, relocating facilities overseas and filling spikes in demand are carefully assessed. A relatively small percentage of firms anticipate that they will exploit risk to
Table 12. SCRM funding source.

\begin{tabular}{ccc}
\hline Source & Survey 1 2009 & Survey 2 2011 \\
\hline General operations budget & 12 & 9 \\
General IT budget & 1 & 2 \\
$\begin{array}{c}\text { Specific departmental budget } \\
\text { General finance budget }\end{array}$ & 20 & 14 \\
$\begin{array}{c}\text { Specific budget to address supply } \\
\text { chain issues } \\
\text { Total }\end{array}$ & 5 & 2 \\
t-test (p $=0.55)$ & 46 & 38 \\
\hline
\end{tabular}

an advantage by taking calculated supply chain risks.

Respondents identified the top five risks that they face (Table 14). The most persistent risks seem to be supplier failure/reliability, supplier bankruptcy, commodity cost volatility, natural disaster, logistic failures and geopolitical events. Respondents were also asked which risks would decrease, remain the same, or increase during the next two years (Table 15). Some of the highest-rated risk factors such as currency exchange rates and government regulations require that SCRM be integrated with ERM in order to most effectively treat the risk.

Risk Treatment Clause 5.5: There were no statistically significant differences in the risk treatment practices (Table 16). When risk is accepted, inventory management and buffering is a widely used option. Risk reducetion emphasized using approved suppliers, while risk sharing emphasized supplier partnering and development.

Monitoring and Review Clause 5.6: There was a statistically significant increase in the monitoring and review practice of using credit and financial data analysis (Table 17). Firms extensively monitor supply chain and SCRM performance using a variety of techniques such as measurement systems, supplier visits, and supplier process monitoring. Relatively few firms benchmark SCRM processes to those of competitors. Firms appear to be somewhat satisfied with supply chain performance (Table 18). There was a statistically significant decrease in satisfaction with damage free and defect free delivery, and a statistically significant increase in satisfaction with reduced material price volatility.

\section{Discussion}

The following research limitations should be kept in mind as the data are interpreted and discussed. The sample size was by design relatively small to ensure a relatively high response rate and to secure participation in following-up interviews. Future research should consider a larger sample. The research findings are based on perceptual data, and while common to survey work, future 
Table 13. SCRM and Clause 5.4 risk assessment.

\begin{tabular}{|c|c|c|c|c|c|}
\hline \multirow[b]{2}{*}{ Risk Assessment Practices and Issues } & \multicolumn{2}{|c|}{ Survey 12009} & \multicolumn{2}{|c|}{ Survey 22011} & \multirow{2}{*}{$\frac{\mathrm{t} \text {-test }}{\mathrm{p}}$} \\
\hline & Mean & SD & Mean & SD & \\
\hline Risks of moving manufacturing facilities overseas are carefully evaluated. & 5.65 & 1.15 & 5.30 & 1.63 & 0.27 \\
\hline Risks of not being able to fulfill a spike in consumer demand are carefully evaluated. & 5.22 & 1.25 & 5.11 & 1.49 & 0.72 \\
\hline Key metrics are in place to measure the risk associated with key suppliers. & 4.65 & 1.68 & 4.68 & 1.60 & 0.95 \\
\hline We apply high levels of analytical rigor to assess our supply chain practices. & 4.37 & 1.53 & 4.38 & 1.78 & 0.98 \\
\hline A key part of our supply chain management is documenting the likelihood \& impact of risks. & 4.20 & 1.67 & 4.19 & 1.60 & 1.00 \\
\hline Taxes such as excise and VAT impact our supply chain decisions. & 3.86 & 1.69 & 4.05 & 1.73 & 0.62 \\
\hline
\end{tabular}

Table 14. Current supply chain risks.

\begin{tabular}{|c|c|c|}
\hline \multirow[b]{2}{*}{ Risk Factor } & \multicolumn{2}{|c|}{ Frequency } \\
\hline & Survey 12009 & Survey 22011 \\
\hline Bankruptcy, ruin, or default of suppliers, shippers, etc. & 22 & 19 \\
\hline Commodity cost volatility & 18 & 15 \\
\hline Natural disasters or accidents (tsunamis, hurricanes, fires, etc.) & 15 & 14 \\
\hline Logistics failure & 20 & 12 \\
\hline Geopolitical event (terrorism, war, etc.) & 6 & 10 \\
\hline Contract failure & 4 & 8 \\
\hline Customer-related (demand change, system failure, payment delay) & 8 & 8 \\
\hline Energy/raw material shortages and power outages & 6 & 8 \\
\hline Information delays, scarcity, sharing, \& infrastructure breakdown & 5 & 6 \\
\hline Government regulations (SOX, SEC, Clean Air Act, OSHA, EU) & 9 & 5 \\
\hline Intellectual property infringement & 7 & 5 \\
\hline Lack of trust with partners & 7 & 5 \\
\hline Diminishing capacities (financial, production, structural, etc.) & 10 & 5 \\
\hline Contamination exposures_-food, germs, infections & 3 & 5 \\
\hline Legal liabilities and issues & 5 & 4 \\
\hline Attracting and retaining skilled labor & 8 & 4 \\
\hline Currency exchange, interest, and/or inflation rate fluctuations & 7 & 4 \\
\hline
\end{tabular}

research should include objective measures (e.g., actual risk reduction outcomes, actual budget, etc.). Responses came mostly from manufacturing firms and future research should include a greater number of service firms to increase generalizability.

Also, the decision to obtain ISO 31000 registration is not always straightforward for managers since many issues still surround the ERM standard. Although ISO 
Table 15. Projected change in supply chain risks.

\begin{tabular}{|c|c|c|c|c|c|c|}
\hline \multirow[b]{2}{*}{ Risk Category } & \multicolumn{3}{|c|}{ Survey 12009} & \multicolumn{3}{|c|}{ Survey 22011} \\
\hline & Less & Same & More & Less & Same & More \\
\hline Commodity cost volatility & 2 & 9 & 33 & 4 & 6 & 28 \\
\hline Banking regulations and tighter financing conditions & 1 & 16 & 28 & 2 & 9 & 27 \\
\hline Government regulations (SOX, SEC, Clean Air Act, OSHA, EU) & 0 & 28 & 16 & 0 & 14 & 24 \\
\hline Supplier failure/reliability & 13 & 7 & 24 & 7 & 14 & 17 \\
\hline Geopolitical event (terrorism, war, etc.) & 0 & 29 & 15 & 0 & 22 & 16 \\
\hline Energy/raw material shortages and power outages & 3 & 26 & 15 & 1 & 21 & 16 \\
\hline Logistics failure & 8 & 27 & 9 & 5 & 17 & 16 \\
\hline Bankruptcy, ruin, or default of suppliers, shippers, etc. & 2 & 13 & 29 & 6 & 16 & 16 \\
\hline Customer-related (demand change, system failure, payment delay) & 3 & 22 & 19 & 2 & 21 & 15 \\
\hline Diminishing capacities (financial, production, structural, etc.) & 5 & 22 & 17 & 5 & 18 & 15 \\
\hline Return policy and product recall requirements & 5 & 29 & 9 & 1 & 23 & 14 \\
\hline Port/cargo security (information, freight, vandalism, sabotage, etc.) & 3 & 29 & 13 & 1 & 24 & 13 \\
\hline Legal liabilities and issues & 2 & 26 & 17 & 1 & 24 & 13 \\
\hline Insurance coverage & 1 & 29 & 14 & 0 & 26 & 12 \\
\hline Tax issues (VAT, transfer pricing, excise, etc.) & 3 & 32 & 9 & 0 & 27 & 11 \\
\hline Intellectual property infringement & 3 & 23 & 18 & 1 & 28 & 9 \\
\hline Attracting and retaining skilled labor & 12 & 15 & 16 & 7 & 22 & 9 \\
\hline Language and educational barriers & 8 & 21 & 15 & 11 & 18 & 9 \\
\hline Strikes_-labor, buyers and suppliers & 4 & 26 & 14 & 4 & 26 & 8 \\
\hline Property development —local codes and requirements & 4 & 35 & 6 & 1 & 30 & 7 \\
\hline Unfamiliar business and property laws & 6 & 36 & 3 & 2 & 29 & 7 \\
\hline Weaknesses in the local infrastructures & 9 & 27 & 8 & 5 & 26 & 7 \\
\hline Contract failure & 5 & 32 & 7 & 6 & 25 & 7 \\
\hline Contamination exposures—food, germs, infections & 5 & 37 & 2 & 3 & 29 & 6 \\
\hline Ethical issues (working practices, health, safety, etc.) & 8 & 30 & 7 & 5 & 27 & 6 \\
\hline Obtaining proper bonds \& licenses & 6 & 35 & 3 & 3 & 30 & 5 \\
\hline Degree of control over operations & 8 & 30 & 6 & 10 & 23 & 5 \\
\hline Measuring tools_-metrics translate differently & 10 & 27 & 7 & 8 & 26 & 4 \\
\hline Lack of trust with partners & 13 & 24 & 7 & 10 & 24 & 4 \\
\hline Internal and external theft & 4 & 36 & 5 & 3 & 32 & 3 \\
\hline Fraud or scandal & 3 & 34 & 7 & 3 & 32 & 3 \\
\hline Information delays, scarcity, sharing, \& infrastructure breakdown & 18 & 18 & 8 & 15 & 20 & 3 \\
\hline
\end{tabular}


Table 16. SCRM and Clause 5.5 risk treatment.

\begin{tabular}{|c|c|c|c|c|c|}
\hline \multirow[b]{2}{*}{ Treatments } & \multicolumn{2}{|c|}{ Survey 12009} & \multicolumn{2}{|c|}{ Survey 22011} & \multirow{2}{*}{$\frac{\mathrm{t} \text {-test }}{\mathrm{p}}$} \\
\hline & Mean & SD & Mean & SD & \\
\hline Inventory management (buffers, safety stock levels, optimal order \& production qty.) & 4.96 & 1.69 & 5.42 & 1.08 & 0.13 \\
\hline Contingency Planning (jointly with suppliers) & 4.22 & 1.25 & 4.63 & 1.50 & 0.18 \\
\hline We have placed an increased focus on inventory management to deal with supply risks. & 4.80 & 1.34 & 4.56 & 1.46 & 0.43 \\
\hline Our suppliers are required to have secure sourcing, business continuity, \& contingency plans. & 4.62 & 1.71 & 4.54 & 1.86 & 0.84 \\
\hline We are prepared to minimize the effects of disruptions (terrorism, weather, theft, etc.) & 3.70 & 1.31 & 3.86 & 1.87 & 0.64 \\
\hline \multicolumn{6}{|l|}{ REDUCTION } \\
\hline Multiple sourcing (rather than sole sourcing) & 4.04 & 1.36 & 4.47 & 1.72 & 0.22 \\
\hline Postponement (delaying the actual commitment of resources to maintain flexibility) & 3.70 & 1.35 & 3.97 & 1.30 & 0.34 \\
\hline \multicolumn{6}{|l|}{ SHARING } \\
\hline Partnership formation and long-term agreements & 5.11 & 1.08 & 5.24 & 1.15 & 0.60 \\
\hline Supplier development initiatives & 4.83 & 1.37 & 5.18 & 1.41 & 0.24 \\
\hline Speculation (forward placement of inventory, forward buying of raw material, etc.) & 4.07 & 1.69 & 4.08 & 1.38 & 0.97 \\
\hline Hedging strategies (to protect against commodity price swings) & 3.61 & 1.63 & 3.92 & 1.62 & 0.38 \\
\hline We are hedging our raw materials exposure to reduce input cost volatility. & 3.78 & 1.49 & 3.65 & 1.69 & 0.72 \\
\hline Joint technology development initiatives & 3.59 & 1.47 & 3.47 & 1.89 & 0.76 \\
\hline
\end{tabular}

Table 17. SCRM and Clause 5.6 monitoring and review.

\begin{tabular}{|c|c|c|c|c|c|}
\hline \multirow[b]{2}{*}{ Process } & \multicolumn{2}{|c|}{ Survey 12009} & \multicolumn{2}{|c|}{ Survey 22011} & \multirow{2}{*}{$\frac{\text { t-test }}{\mathrm{p}}$} \\
\hline & Mean & $\mathrm{SD}$ & Mean & $\mathrm{SD}$ & \\
\hline Supplier performance measurement systems & 5.35 & 1.61 & 5.71 & 1.64 & 0.31 \\
\hline Credit and financial data analysis & 4.54 & 1.60 & 5.37 & 1.34 & $0.01 *$ \\
\hline Business process management & 4.65 & 1.37 & 5.11 & 1.27 & 0.12 \\
\hline Consistent monitoring and auditing of a supplier's processes & 4.59 & 1.72 & 5.03 & 1.68 & 0.24 \\
\hline Spend management and analysis & 4.85 & 1.53 & 5.03 & 1.70 & 0.62 \\
\hline Contract management (e.g., leverage tools to monitor performance against commitments) & 4.48 & 1.64 & 5.00 & 1.52 & 0.14 \\
\hline Benchmarking (internal, external, industry-wide, etc.) & 4.59 & 1.54 & 4.68 & 1.51 & 0.77 \\
\hline We have placed an emphasis on incident reporting to decrease the effects of disruptions. & 4.50 & 1.43 & 4.49 & 1.76 & 0.97 \\
\hline Inventory optimization tools & 4.78 & 1.66 & 4.49 & 1.68 & 0.43 \\
\hline Training programs & 3.54 & 1.59 & 3.79 & 1.66 & 0.49 \\
\hline We use network design and optimization tools to cope with uncertainty in the supply chain. & 3.66 & 1.85 & 3.67 & 1.64 & 0.98 \\
\hline We actively benchmark our supply chain risk processes against competitors. & 3.57 & 1.68 & 3.39 & 2.02 & 0.67 \\
\hline
\end{tabular}


Table 18. Performance satisfaction.

\begin{tabular}{|c|c|c|c|c|c|}
\hline \multirow[b]{2}{*}{ Outcome } & \multicolumn{2}{|c|}{ Survey 12009} & \multicolumn{2}{|c|}{ Survey 22011} & \multirow{2}{*}{$\frac{\mathrm{t} \text {-test }}{\mathrm{p}}$} \\
\hline & Mean & $\mathrm{SD}$ & Mean & $\mathrm{SD}$ & \\
\hline Logistics and delivery reliability & 4.96 & 1.01 & 5.32 & 1.25 & 0.15 \\
\hline Meeting customer service levels & 5.07 & 1.20 & 5.19 & 1.17 & 0.64 \\
\hline Damage-free and defect-free delivery & 5.41 & 0.83 & 5.00 & 0.94 & $0.04^{*}$ \\
\hline Order completeness and correctness & 4.96 & 1.11 & 4.86 & 1.29 & 0.73 \\
\hline After sales service performance & 4.57 & 1.29 & 4.86 & 1.09 & 0.27 \\
\hline Inventory management & 4.52 & 1.22 & 4.84 & 1.32 & 0.27 \\
\hline Reduced disruptions in the supply chain & 4.59 & 1.15 & 4.54 & 1.07 & 0.85 \\
\hline Reduced material price volatility & 3.80 & 1.51 & 4.32 & 1.06 & $0.07^{*}$ \\
\hline Lower commodity prices & 3.98 & 1.27 & 4.05 & 1.20 & 0.78 \\
\hline
\end{tabular}

31000 addresses several criticisms of previous ERM frameworks [8,21-23], it is still met with uncertainty and this uncertainty could have impacted the survey findings. Most of this uncertainty is related to perceived weaknesses with regard to its ability to deliver real benefits and a continued over-emphasis on bureaucratic processes and documentation. Other criticisms generally concern inappropriate misapplication or extension of its use in companies, and the effect this can have on organizational resources and culture. While the criticism focuses on the standard, the problems typically arise from a failure of organizations to understand the underlying philosophy of the standard and the idea, which is a process-driven systematic approach to ERM.

\subsection{Longitudinal Data Analysis and SCRM Trends}

The primary reason for using longitudinal data was to determine if over time the ISO 31000 framework provided a foundation for both researchers and managers to discuss, examine, and/or implement SCRM strategies and practices. There is a reasonable alignment between proposed SCRM frameworks, actual SCRM practices and ISO 31000:2009. So, if it is true that adopting a consensus framework for SCRM research will enable better communication between researchers and practitioners, so that such a common framework would enable more efficient and effective research to close research gaps [7], then ISO 31000:2009 provides a reasonable foundation.

A secondary reason for employing longitudinal data was to identify trends in supply risks, strategies, and practices. There were only four statistically significant changes identified. There was an increase in agreement that without a systematic analysis technique to assess risk, much can go wrong in a supply chain. As will be discussed subsequently, it doesn't appear that this awareness has translated into SCRM being raised to a strategic corporate level through linkages with ERM, or into an increased allocation of resources for SCRM. ISO 31000 may provide a foundation for practitioners to remedy those situations.

There was a statistically significant increase in the use of credit and financial data analysis, likely driven by the high level of supplier failures and bankruptcies over the last decade. Firms reported statistically significant better performance in terms of reducing material price volatility. It is not possible to identify specific drivers of this improved performance without controlling for many broad economic factors. Hedging strategies were not widely used, so this is unlikely a driver. Perhaps the relatively high use of supplier partnering, approved supplier lists and increased use of supplier financial health assessment helped create some price stability. There was a decrease in satisfaction with damage-free and defect-free delivery performance. Again, the direct causes of this outcome are not readily identifiable. The examination of direct cause and effect relationships was beyond the scope of this research. It was also clear that some of the survey responses were linked to the economic recession conditions of 2008. For example, a major risk and source of supply chain disruption was supplier bankruptcy, for which most buying organizations were not proactively evaluating. Future research should explore such relationships and over a period of time that goes beyond the two years covered in this study to see how companies have managed this and other risk issues since. 


\subsection{SCRM Practices Relative to ISO 31000 Clauses}

Clause 5.2 Communication and Consultation: The importance of reliable and timely information communicated throughout the value chain was evident. One manager highlighted this importance: "We have a very intricate web of parts supply. It can be very difficult to get accurate information about our suppliers and even our own company overseas. Many times, it is difficult to know where to obtain information accurately and reliably. So, even if we have a perfect system or structure in place to manage risk, it depends on the input of reliable data that accurately identifies the risk. The old "garbage in/garbage out' theory applies."

Not only was the ability to find reliable information a challenge for some firms, the ability to share information quickly was also a challenge. One manager noted that the major failure mode was "information speed that is too reactive versus proactive." Some firms indicated that such challenges can be overcome by matching information research efforts with project needs: "In many cases getting good information can be as simple and cheap as subscribing to a few periodicals, or as complex and expensive as hiring outside consultants. It really depends on the business that you're in and the needs of the company."

Clause 5.3 Establishing the Context: Proposed SCRM frameworks as well as SCRM strategies and practices used by respondents align well with the ISO 31000 process. However, it does not appear that the firms are proactively using ISO 31000 or any other such integrative framework for SCRM. Even at firms with seemingly advanced SCRM practices, the linkage to ERM seems a bit weak. One manager stated that "supply risk management is handled at the plant location level and not from the corporate level. This is created by a 'we have always done it this way' mentality. It has always worked in the past because changes to production plans have never fluctuated like this before, both up and down. This challenge is preventing us from accurately assessing which suppliers are at risk and why, and assessing this early enough to do something about it."

ISO 31000 states that upper managers need to take the lead in ERM and SCRM to establish the appropriate culture, organization, budget, resources, and processes for managing risks. A few respondents suggested that their firms have recently taken steps in this direction, as exemplified by one manager's comment: "Resources have been allocated to SCRM as we have increased the amount of Full Time Headcount dedicated to supply chain activities across the company. We have also received IT prioritization for projects that will help us understand exposure related to certain supply relationships and allow us to take action on those. As we continue to broaden our business and create revenue streams generated from $100 \%$ supplied product, we have a more direct association of revenue risk with the supply chain.”

Such strategic linkage of SCRM to ERM was not universal. When support from upper management was lacking, most respondents suggested that it was up to the supply group to make a solid business case for SCRM, as summarized by one manager: "As supply managers, we need to have an effective way to tie a supplied product or component back to actual revenue generated from that product or component. Many companies including ours need to make the process easier and more visible to upper management once the data is retrieved. The financial impact-favorable or unfavorable-as well as the financial risk and exposure should be captured by the supply managers and communicated up through upper management."

The lack of SCRM linkage to ERM is further evidenced in the organization section of Table 8. Few supply personnel understand government legislation, geopolitical issues, or the activities being performed by the firm's risk management group. Perhaps supply chain curriculum needs to put a greater emphasis on such issues, or companies need to hire supply personnel with more varied experiences and backgrounds.

Despite "non-trivial" amounts being spent on SCRM and most firms increasing the budget for SCRM, the overall perspective was that budgets were not sufficiently "high." Supply managers suggested that their ability to mitigate supply chain risks was often limited by a lack of money, time, or people. The current business environment and focus on lean operations suggested that secureing more resources for SCRM is now even more challenging. One manager stated: "In the current state of the economy with pressure for reduced cost and leaner manufacturing, it's harder to have the resources-people and funding - to be fully prepared for these risks, which greater puts a company in the face of danger.” As stated earlier, it is up to the supply manager to make a business case for SCRM. Perhaps it is the failure to make a business case that explains why the budget for SCRM most often is established in departments other than supply.

Relatively few firms indicated that their company takes a proactive risk management approach. The firms that had this perspective recognized that communications and involvement with upper management was the key: "Our top management has a reoccurring meeting where various plants get together and discuss suppliers that are putting our business at risk. Sources of risk can be financial—bankruptcy, paying sub suppliers, resources and capacity risk, or price risk. Meeting on these issues frequently allows top management to be aware of the issues and adjust business outlooks if needed."

Clause 5.4 Risk Assessment: Most firms identify a 
wide range of risks and then prioritize those risks in terms of potential impact and/or likelihood of occurrence. One manager cautioned that focusing on high priority risks makes good sense, but perhaps it is the interaction of multiple moderate risks that in combination result in the most significant risk. Future research might examine the use of "design of experiments" to assess risk.

The most frequently cited and persistent risk factor was supplier failure/reliability. Some firms recognized that part of the problem is their own doing. One manager commented that "the automotive industry and their negotiating techniques have ruined and shut down suppliers. The cost pressures are immense in today's economy, forcing customers to squeeze their suppliers." Future research may explore the impact that internal company processes (e.g., lean initiatives, cost reduction or target costing programs, product variety and proliferation) have on creating supply risks.

Quite a few of the most frequently cited and increasing risk factors are beyond the control of supply managers (e.g., natural disasters, geopolitical events, increasing government regulations, currency fluctuations, etc.). Companies tend to treat such risks using dual sourcing or buffer inventories. Somewhat surprising was that fewer firms used hedging strategies or speculation techniques. Perhaps this was due to the lack of supply personnel understanding such issues as previously discussed.

Clause 5.5 Risk Treatment: Partnerships were extensively used to share risks, though few firms used joint technology development to share risk. This is somewhat surprising because it is generally agreed that risk management is most efficient and effective when done early in a product lifecycle. Given an increasing focus on "open innovation" in the last decade, perhaps more firms will partner not only for innovation but for risk reduction as well during new product development. One manager commented that this will be a challenge because SCRM analysis takes time and anything that might hold up new product development time is unlikely to be implemented.

Companies rely extensively on qualification of approved suppliers to reduce risks. One manager commented that such lists are important, but the assessments are generally based on past performance and may not be indicative of future performance. Forward-looking risk assessment measures tended to be limited and very subjective. One respondent indicated that forward looking measures such as supplier scalability (e.g., supplier ability to develop global reach) and supplier-supply chain management skills (i.e., supplier's ability to manage its own supply chain) needed to be included in supplier qualification systems to prevent future risks.

Clause 5.6 Monitoring and Review: Without ongoing monitoring and control, supplier performance may degrade after qualification, and then risks will surface over time. Companies monitor and control SCRM and supply chain performance using traditional performance measures such as cost, quality, delivery, etc. Though SCRM impacts such performance outcomes, most firms would like to develop risk specific measures to help them make the business case for more investments in SCRM. One manager commented: "I think we could have more clear-cut metrics that are directly related to supply chain risk, rather than some of the indirect ones that we have now. But to create new metrics always requires funding, which at this time isn't being used for more metric development." In the meantime, firms will continue to monitor performance by conducting traditional supplier visits and using supplier scorecards. Without knowing in advance how to measure SCRM strategy performance, one option is to adopt a learning organization perspective as suggested by one manager: "I'm not sure we have an official way of reviewing if a risk strategy was as effecttive as others. If we avoided a risk, we consider that a success. If we still got exposed to a risk despite our strategy, we'll review lessons learned and then adjust the strategy to incorporate that.”

Supply managers are rarely compensated specifically for SCRM efforts, in part due to the difficulty of proving that without risk treatment the result would have been worse. Compensation for "risk management" is generally based on traditional supply chain performance measures and one manager stated: "Risk performance evaluation is tracked through the review process, and performance ratings are given based on performance to key objectives. Employees also receive a bonus based on actual business performance - we reduce risk, business performance is strong." In most cases however, there was no specific bonus or compensation for risk management: "Typically the people working on risk management are the same people working with the suppliers on a daily basis, so no further compensation is given. At a global supply chain management level, risk management is a larger part of their day-to-day responsibilities, but more from a coordination of efforts level than a working level, and still no additional compensation.”

Respondents seemed relatively satisfied with supply chain performance along multiple dimensions, though all respondents recognized the need for continuous improvement. Some progress was made in controlling price volatility as previously discussed. Again, whether or not these performance outcomes can be directly tied to SCRM is unclear.

\subsection{Implications for Managers}

The findings suggest that firms are very concerned about supply chain risks and that they spend significant effort managing those risks. However, it doesn't seem that firms take a long-term approach to SCRM by integrating 
such efforts with ERM, and that making a business case for SCRM will remain a challenge. One manager stated: "We don't have a dedicated set of resources for risk management. We take the approach that it's everyone's responsibility. Good in theory, but during very busy parts of the year, other commitments may take the focus off risk management, thus leaving us open to issues. The challenge in creating a dedicated group to manage this is always money. Is it worth it? To overcome this, you'd need to look at the cost of the resources, people, and technology and balance that against the costs that are avoided by having the group in place. This calculation would likely involve a lot of soft costs and could be difficult to get agreement on, thus making it a tougher sell.” This perspective was shared by many respondents to our survey. Given that SCRM efforts map well to the ISO 31000 standard, perhaps supply managers will be able to strengthen the business case for SCRM and create a linkage of SCRM to ERM by deploying the "missing link," the ISO 31000 standard.

\subsection{Implications for Researchers}

A few future research topics were already presented in the discussion section. For example, research that includes service purchases and/or service firms is warranted. The exploration of direct cause-and-effect relationships is also of interest (e.g., what is the best response to a parts shortage caused by a hurricane versus a parts shortage driven by limited supply capacity?). A suggestion was also made that examining the impact and treatment of the interaction of risks might advance our understanding of SCRM. Further, research regarding the impact of buying firm strategy and process (e.g., lean initiatives, cost reduction, product proliferation) on driving supply risks was suggested. The following topics expand on such issues.

Topic 1: Can our understanding of SCRM be supported and accelerated by adoption of the ISO 31000 framework? The literature review suggested that ISO 31000 is more comprehensive than current SCRM frameworks, that SCRM is considered a subset of ERM [7], and that ISO 31000 may become an internationally implemented ERM standard [26]. Perhaps SCRM researchers should adopt the ISO 31000 framework so that agreement on definitions, terms, scales, etc., will be reached to support in-depth SCRM research.

Topic 2: Does ERM/SCRM provide appropriate return on investment? Firms with well established SCRM strategies and structures respond more effectively, at least in the short term, to major supply disruptions than firms without such structures. However, such significant disruptions tend to be rare. It has been suggested that different structures and approaches to SCRM provide different results. For example, one effort found that
SCRM implementation impacts supply performance, but reactive SCRM provided better disruption resilience and reduction of the bullwhip effect while preventive SCRM provided better values concerning flexibility and safety stocks [52]. Ultimately, does an established department, system, and resources dedicated to SCRM pay for itself in the long term, and if so, what is the appropriate structure?

Topic 3: Related to Topic 2, what is the most effective organizational structure for effective SCRM? Initiatives such as Six Sigma have called for different levels of specialization (e.g., black and green belts), yet they still maintained that quality is the responsibility of each person. Even lean initiatives call for a somewhat hierarchical structure of expertise (e.g., group leader, team leader), yet they maintained that waste reduction and flow are everybody's responsibility. Should a separate SCRM department be created, or should it be part of the ERM organization? Should a hierarchical structure of risk experts be developed, or should SCRM be part of each supply person's everyday responsibilities? Or, perhaps the most effective SCRM approach would be to outsource it. The increased use of 3PL/4PL, supply chain consultants, information brokers and analysts such as $\mathrm{D} \& \mathrm{~B}$, government or industry regulations (e.g., GAAP, SOX, etc.) and international standards (e.g., ISO 9000, ISO 14000) already provide support for SCRM outsourcing.

Topic 4: To what extent should SCRM be integrated into new product development efforts? Collaboration with suppliers for new product development has increased in the past decade. A primary objective of such efforts is to innovate, but part of all such processes are to address technology risks early. How can firms most effectively "design for supply risk" without delaying new product development efforts. Perhaps the "rapid plant assessment" process [53] provides a good starting point for a "rapid risk assessment" process.

Topic 5: What is the role for IT, and how can companies more efficiently integrate new IT to support SCRM? This research suggested that firms use IT for SCRM by gathering and disseminating data, communicating with suppliers, measuring performance, and managing inventtory. However, few firms used IT for SCRM by creating data warehouses, integrating supplier into new product development, analyzing network designs analysis, or optimizing inventory. Advancements in IT applications, including for example cloud computing, tablets and mobile devices, enable firms to gather and distribute realtime data. Research that identifies proper strategies for the use and effective adoption of such tools is warranted.

\section{Acknowledgements}

The authors would like to take this opportunity to thank 
the following Western Michigan University undergraduate students for their participation in this research project: Mr. Jamie A. Loeks, Mr. Judson A. McCulloch, and Ms. Priyanka Parekh.

\section{REFERENCES}

[1] D. Wu, D. Olson and J. Birge, "Introduction to Special Issue on 'Enterprise Risk Management in Operations'," International Journal of Production Economics, Vol. 134, No. 1, 2011, pp. 1-2. http://dx.doi.org/10.1016/j.ijpe.2011.07.002

[2] R. Hoyt and A. Liebenberg, "The Value of Enterprise Risk Management,” Journal of Risk and Insurance, Vol. 78, No. 4, 2011, pp. 795-822. http://dx.doi.org/10.1111/j.1539-6975.2011.01413.x

[3] C. Smithson and B. Simkins, "Does Risk Management Add Value? A Survey of the Evidence," Journal of Applied Corporate Finance, Vol. 17, No. 3, 2005, pp. 8-17. http://dx.doi.org/10.1111/j.1745-6622.2005.00042.x

[4] M. Beasley, R. Clune and D. Hermanson, "ERM: A Status Report,” The Internal Auditor, Vol. 62, No. 1, 2005, pp. 67-72.

[5] L. Hauser, "Risk Adjusted Supply Chain Management," Supply Chain Management Review, Vol. 7, No. 6, 2003, pp. 64-71.

[6] R. VanderBok, J. Sauter, C. Bryan and J. Horan, "Manage Your Supply Chain Risk," Manufacturing Engineering, Vol. 138, No. 3, 2007, pp. 153-161.

[7] M. S. Sodhi, B. G. Son and C. S. Tang, "Researcher's Perspective on Supply Risk Management," Productions and Operations Management, Vol. 21, No. 1, 2012, pp. 1-13. http://dx.doi.org/10.1111/j.1937-5956.2011.01251.x

[8] R. Tummala and T. Schoenherr, “Assessing and Managing Risks Using the Supply Chain Risk Management Process (SCRMP)," Supply Chain Management, Vol. 16, No. 6, 2011, pp. 474-483. http://dx.doi.org/10.1108/13598541111171165

[9] O. Tang and S. N. Musa, "Identifying Risk Issues and Research Advancements in Supply Chain Risk Management," International Journal of Production Economic, Vol. 133, No. 1, 2011, pp. 25-34. http://dx.doi.org/10.1016/j.ijpe.2010.06.013

[10] S. Black and L. Porter, "Identification of the Critical Factors of TQM,” Decision Sciences Journal, Vol. 27, No. 1, 1996, pp. 1-21. http://dx.doi.org/10.1111/j.1540-5915.1996.tb00841.x

[11] N. Capon, M. Kaye and M. Wood, "Measuring the Success of a TQM Programme," International Journal of Quality and Reliability Management, Vol. 12, No. 8, 1994, pp. 8-22. http://dx.doi.org/10.1108/02656719510097471

[12] S. Curkovic, S Melnyk, R. Calantone and R. Handfield. "Validating the Malcolm Baldrige National Quality Framework Through Structural Equation Modeling," International Journal of Production Research, Vol. 38, No. 4, 2000, pp. 765-791.

http://dx.doi.org/10.1080/002075400189149
[13] J. Dean and D. Bowen, "Management Theory and Total Quality: Improving Research and Practice through Theory Development," Academy of Management Journal, Vol. 19, No. 3, 1994, pp. 392-418.

[14] B. Flynn, R. Schroeder and S. Sakakibara, “A Framework for Quality Management Research and an Associated Instrument,” Journal of Operations Management, Vol. 11, No. 4, 1994, pp. 339-366. http://dx.doi.org/10.1016/S0272-6963(97)90004-8

[15] V. Saraph, P. Benson and R. Schroeder, “An Instrument for Measuring the Critical Factors of Quality Management,” Decision Sciences, Vol. 20, No. 4, 1989, pp. 810829.

http://dx.doi.org/10.1111/j.1540-5915.1989.tb01421.x

[16] B. Nocco and R. Stulz, "Enterprise Risk Management: Theory and Practice,” Journal of Applied Corporate Finance, Vol. 18, No. 4, 2006. pp. 8-20. http://dx.doi.org/10.1111/j.1745-6622.2006.00106.x

[17] D. Bowling and L. Rieger, "Making Sense of COSO's New Framework for Enterprise Risk Management,” Bank Accounting \& Finance, Vol. 18, No. 2, 2005, pp. 35-40.

[18] C. Chapman, "Bringing ERM into Focus,” The Internal Auditor, Vol. 60, No. 3, 2003, pp. 30-35.

[19] B. Ballou and D. Heitger, “A Building Block Approach for Implementing COSO's Enterprise Risk Management-Integrated Framework,” Management Accounting Quarterly, Vol. 6, No. 2, 2005, pp. 1-10.

[20] A. Samad-Khan, "Why COSO Is Flawed," Operational Risk, Vol. 6, No. 1, 2005, pp. 24-28.

[21] J. Hallikas, I. Karvonen, U. Pulkkinen, V. M. Virolainen and M. Tuominem, "Risk Management Processes in Supplier Networks," International Journal of Production Economics, Vol. 90, No. 1, 2004, pp. 47-58. http://dx.doi.org/10.1016/j.ijpe.2004.02.007

[22] P. R. Kleindorfer and G. H. Saad, "Managing Disruptions in Supply Chains,” Production and Operations Management, Vol. 14, No. 1, 2005, pp. 53-68. http://dx.doi.org/10.1111/j.1937-5956.2005.tb00009.x

[23] I. Manuj and J. T. Mentzer, "Global Supply Chain Risk Management,” Journal of Business Logistics, Vol. 29, No. 1, 2008, pp. 133-156. http://dx.doi.org/10.1002/j.2158-1592.2008.tb00072.x

[24] M. Moody, “ERM \& ISO 31000,” Rough Notes, Vol. 153, No. 3, 2010, pp. 80-81.

[25] ISO, "ISO 31000:2009, Risk Management-Principles and Guidelines," International Standards Organization, Geneva, 2009.

[26] D. Gjerdrum and W. Salen, "The New ERM Gold Standard: ISO 31000:2009,” Vol. 55, No. 8, 2010, pp. 43-44.

[27] “AS/NZS. AS/NZS 4360:2004,” Risk Management Standard, Wellington, 2007.

[28] ISO, "ISO Guide 73:2009, Risk Management-Vocabulary,” International Standards Organization, Geneva, 2009.

[29] G. Purdy, "ISO 31000:2009—Setting a New Standard for Risk Management,” Risk Analysis, Vol. 30, No. 6, 2010, pp. 881-886. http://dx.doi.org/10.1111/j.1539-6924.2010.01442.x 
[30] J. Blackhurst, T. Wu and P. O’Grady, "PDCM: A Decision Support Modeling Methodology for Supply Chain, Product and Process Design Decisions," Journal of Operations Management, Vol. 23, No. 3-4, 2005, pp. 325343. http://dx.doi.org/10.1016/j.jom.2004.05.009

[31] S. Kumar and J. Verruso, "Risk Assessment of the Security of Inbound Containers at US Ports: A Failure, Mode, Effects, and Criticality Analysis Approach,” Transportation Journal, Vol. 47, No. 4, 2008, pp. 26-41.

[32] Z. Liu and J. Cruz, "Supply Chain Networks with Corporate Financial Risks and Trade Credits Under Economic Uncertainty," International Journal of Production Economics, Vol. 137, No. 1, 2012, pp. 55-67. http://dx.doi.org/10.1016/j.ijpe.2012.01.012

[33] G. Zsidisin and J. Hartley, "A Strategy for Managing Commodity Price Risk," Supply Chain Management Review, Vol. 1, No. 2, 2012, pp. 46-53.

[34] G. Zsidisin and S. Wagner, "Do Perceptions become Reality? The Moderating Role of Supply Chain Resiliency on Disruption Occurrence,” Journal of Business Logistics, Vol. 31, No. 2, 2010, pp. 1-20.

http://dx.doi.org/10.1002/j.2158-1592.2010.tb00140.x

[35] C. S. Tang, "Perspectives in Supply Chain Risk Management," International Journal of Production Economics, Vol. 103, No. 2, 2006, pp. 451-488.

http://dx.doi.org/10.1016/j.ijpe.2005.12.006

[36] M. Laeequddin, G. D. Sardana, B. S. Sahay, K. Abdul Waheed and V. Sahay, "Supply Chain Partners Trust Building Process through Risk Evaluation: The Perspectives of UAE Packaged Food Industry,” Supply Chain Management, Vol. 14, No. 4, 2009, pp. 280-290. http://dx.doi.org/10.1108/13598540910970117

[37] O. Khan and B. Burnes, "Risk and Supply Chain Management: A Research Agenda,” The International Journal of Logistics Management, Vol. 18, No. 2, 2007, pp. 197216. http://dx.doi.org/10.1108/09574090710816931

[38] G. A. Zsidisin, L. M. Ellram, J. R. Carter and J. L. Cavinato, “An Analysis of Supply Risk Assessment Techniques," International Journal of Physical Distribution \& Logistics Management, Vol. 34, No. 5, 2004, pp. 397-413. http://dx.doi.org/10.1108/09600030410545445

[39] K. Inderfurth and P. Kelle, "Capacity Reservation under Spot Market Price Uncertainty,” International Journal of Production Economics, Vol. 133, No. 1, 2011, pp. 272279. http://dx.doi.org/10.1016/j.ijpe.2010.04.022

[40] M. Giannakis and M. Louis, "A Multi-Agen Based Framework for Supply Chain Risk Management,” Journal of Purchasing and Supply Management, Vol. 17, No. 1, 2001, pp. 23-31. http://dx.doi.org/10.1016/j.pursup.2010.05.001

[41] E. Holschbach and E. Hofmann, "Exploring Quality Management for Business Services from a Buyer's Perspective Using Multiple Case Study Evidence,” International Journal of Operations \& Production Management, Vol.
31, No. 6, 2011, pp. 648-685.

http://dx.doi.org/10.1108/01443571111131980

[42] D. Kern, R. Moser, E. Hartman and M. Moder, "Supply Risk Management: Model Development and Empirical Analysis," International Journal of Physical Distribution \& Logistics Management, Vol. 42, No. 1, 2012, pp. 60-82. http://dx.doi.org/10.1108/09600031211202472

[43] C. Y. Chiang, C. Kocabasoglu-Hillmer and N. Suresh, “An Empirical Investigation of the Impact of Strategic Sourcing and Flexibility on Firms Supply Chain Agility,” International Journal of Operations and Production Management, Vol. 32, No. 1, 2012, pp. 49-78. http://dx.doi.org/10.1108/01443571211195736

[44] S. Matook, R. Lasch and R. Tamaschke, "Supplier Development with Benchmarking as Part of a Comprehensive Supplier Risk Management Framework," International Journal of Operations and Production Management, Vol. 29, No. 3, 2009, pp. 241-267. http://dx.doi.org/10.1108/01443570910938989

[45] M. Christopher, C. Mena, O. Khan and O. Yurt, “Approaches to Managing Global Sourcing Risk," Supply Chain Management, Vol. 16, No. 2, 2011, pp. 67-81. http://dx.doi.org/10.1108/13598541111115338

[46] K. Eisenhardt, "Building Theories from Case Study Research,” The Academy of Management Review, Vol. 14, No. 4, 1989, pp. 532-550.

http://dx.doi.org/10.5465/AMR.1989.4308385 http://dx.doi.org/10.2307/258557

[47] C. Voss, N. Tsikriktsis and M. Frohlich, "Case Research in Operations Management,” International Journal of Operations \& Production Management, Vol. 22, No. 2, 2002, pp. 195-219. http://dx.doi.org/10.1108/01443570210414329

[48] M. Miles and A. Huberman, "Qualitative Data Analysis: A Sourcebook of New Methods,” Sage Publications, Newbury Park, 1984.

[49] B. Glaser and A. Strauss, "The Discovery of Grounded Theory: Strategies for Qualititative Reasearch,” Aldine, Chicago, 1967.

[50] D. M. McCutcheon and J. R. Meridith, "Conducting Case Study Research in Operations Management," Journal of Operations Management, Vol. 11, No. 3, 1993, pp. 239256. http://dx.doi.org/10.1016/0272-6963(93)90002-7

[51] J. S. Armstrong and T. S. Overton, "Estimating Nonresponse Bias in Mail Surveys," Journal of Marketing Research, Vol. 14, No. 3, 1977, pp. 396-402. http://dx.doi.org/10.2307/3150783

[52] J. H. Thun and D. Hoening, "An Empirical Analysis of Supply Chain Risk Management in the German Automotive Industry," International Journal of Production Economics, Vol. 131, No. 1, 2011, pp. 242-249. http://dx.doi.org/10.1016/j.ijpe.2009.10.010

[53] R. E. Goodson, "Read a Plant-Fast," Harvard Business Review, Vol. 80, No. 5, 2002, pp. 105-113. 